\title{
INFLUJO DE LA NARRATIVA RUSA EN DOÑA EMILIA PARDO BAZÁN. EL EJEMPLO DE LA PIEDRA ANGULAR
}

\author{
Mercedes ETREROS \\ Universidad Complutense
}

Constituye la obra de doña Emilia Pardo Bazán un hito en la historia de la literatura española del siglo XIX, y supone un centro de interés desde distintos aspectos de la historia literaria. Por ejemplo, desde las teorías recepcionales, pues fue la escritora más leída de su tiempo, después de Pérez Galdós, dato importante para conocer las características de lo que la escuela histórica mencionada entiende como horizonte de expectativas de un período dado; asimismo, fue muy admirada por algunos de los escritores de la llamada "Generación del 98"; el profesor Rubia Barcia (1960, pp. 240-263) investiga, por ejemplo, su influencia en Unamuno, dato de interés para la interpretación de la literatura española de principios del siglo XX, y la recepción literaria de los movimientos que se dan en España. Sin embargo, la mayor trascendencia en cuanto a la incidencia histórico-literaria se encuentra en las constantes indagaciones de la autora en movimientos literarios y de creación: de todos los escritores españoles del siglo XIX, es doña Emilia la que por excelencia rompe las barreras que tradicionalmente separan a España de Europa. El europeísmo de Pardo Bazán es un hecho que va a trascender no sólo a su obra, sino a la de toda su generación, pues en gran medida la entrada y consolidación de movimientos literarios decimonónicos como el Realismo, el Naturalismo o el Simbolismo, hay que estudiarlos de su mano.

No vamos a insistir acerca de la deuda de la literatura española con el realismo de los hermanos Goncourt, con el naturalismo de Emile Zola o con el llamado psicologismo de Bourget, ampliamente estudiada, cuyos principios literarios son difundidos y practicados por Pardo Bazán. Alegatos de la importancia y de la magnitud cualitativa de La cuestión palpitante pueden encontrarse también en ideas y críticas posteriores de la escritora, como la que vamos a abordar acerca de la novela rusa decimonónica. En carta a Narcis Oller, fechada el 12 de Octubre de 1896, escribe doña Emilia: 
¿En qué trabajo ahora?... Estoy en el corazón de Rusia. Quiero hacer un estudio sobre esa extraña y curiosa literatura, como ya se lo anuncié creo que en París. En España creo ser una de las pocas personas que tienen la cabeza para mirar lo que pasa en el extranjero. Aquí, a nuestro modo, somos tan petulantes como pueden serlo los franceses, y nos figuramos que más allá del Ateneo y San Jerónimo no hay pensamiento ni vida estética; ;error peregrino cuya enormidad nos asusta así que atravesamos el Pirineo!...

Dada la importancia que suscitó La cuestión palpitante en su momento, la crítica le ha conferido especial relieve, y, por el contrario, ha sido relativamente poco estudiada esta otra visión literaria que doña Emilia defendió y difundió a partir de 1886-1887, y tampoco se ha indagado suficientemente en qué medida este fenómeno mediatizó los cambios que se producen en su propia práctica narrativa y en la que los grandes novelistas españoles decimonónicos, como Palacio Valdés, Clarín o el mismo Pérez Galdós.

En principio, el que un escritor cambie fundamentalmente su manera de concebir la creación no es fácil, ni es frecuente en la historia de la literatura. Ahora bien, según las teorías hermenéuticas, la obra literaria es una interpretación del mundo, y esa interpretación sí es susceptible de cambio si la ideología o la visión del mundo cambian o evolucionan. En este caso, hay aspectos de la interpretación e incluso de la percepción que sí varían. Un caso paradigmático sería precisamente el de doña Emilia Pardo Bazán. Veamos un ejemplo: los móviles del suicidio de El cisne de Vilamorta, de 1884, nada tienen que ver con los de Morriña, de1889, y ninguno de los dos con los de La piedra angular, de 1891. En el primer caso es un suicidio típicamente zoliano, producto de una fatal pasión amorosa y del fallo del psiquismo femenino; en Morriña también hay una fuerte dosis de naturalismo, centrado esta vez en la "raza": Esclavitud muere de morriña, de saudade, y la novela acaba con una curiosa explicación de la autora, que en un virtuosismo estratégico de inclusión de lector implícito escribe: "Si consultamos sobre este drama a don Gabriel Pardo, nos dirá que el extravío mental que conduce a la muerte voluntaria es muy propio del sombrío humor de la raza céltica, esa gran vencida de la Historia". En La piedra angular, el suicidio traerá consigo la redención.

La división NATURALISMO/ESPIRITUALISMO marca las fuentes de influjo tradicionalmente admitidas. En este sentido, hay un momento en la obra de Pardo Bazán que la crítica denomina "segunda manera", "otra manera"; de hecho está muy claro que, a partir de 1905, año en que publica La quimera, doña Emilia escribe dentro de unos cánones que la historia de la literatura francesa conoce como psicologismo, y que antes de 1884, en La Tribuna, por ejemplo, el influjo del naturalismo es decisivo. Sin embargo, existen unas obras intermedias de más difícil clasificación, escritas en unos años que Valera Jácome denomina "Período de basculación estética" (Varela Jácome, 1973, pp. 97 y ss.).

Insiste doña Emilia en que su finalidad es "crear belleza", mas habría que preguntarse qué entiende por tal después de las concepciones estéticas del Romanticismo y del Realismo, y en este punto hay que considerar obligadamente 
el prólogo de Cromwell, y ya en el ámbito español, y en plena vigencia del Realismo-Naturalismo, el caso de don Juan Valera, quien admite desvirtuar la realidad en pro de la belleza.

Para centrar el tema que nos ocupa hemos de remitirnos a dos trabajos de importancia dentro de la crítica dedicada a Pardo Bazán. Se trata de la visión de Nelly Clemessy expuesta en Emilia Pardo Bazán, romancière (La crítique, la théorie, la pratique), que encuentra en las novelas de los años noventa una transición entre las fases naturalista y espiritualista; y la de Maurice Hemingway en Emilia Pardo Bazán. The making of a novelist, que ha llegado a conclusiones verdaderamente interesante en las que puede leerse: "I believe to be Pardo Bazán's grouth into maturity as a novelist in the late 1880s. and 1990s.". Nelly Clemessy se fija en el cambio de ambientación de las novelas; y Hemingway en la inclusión del psicologismo, que hace somera aparición, dice, en El cisne de Vilamorta ${ }^{1}$. En las obras escritas entre 1890 y 1896 es donde Hemingway centra su análisis, por considerar que son las de mayor interés de la novelista: "these novels - escribe en la página 2- have been almost entirely neglected, and all but the first (se refiere a Una cristiana) seem to me represent Pardo Bazán's work at its best". Otra de sus conclusiones es que, entre las novelas que cierran la producción del siglo XIX, no encuentra decisivo el influjo de Bourget, y obras tan interesadas en la psicología amorosa como Deuxième amour o Un crime d'amour, antítesis de la idealización romántica, fueron muy poco del agrado de la escritora ${ }^{2}$.

Desembocamos con estas conclusiones en la hipótesis del presente estudio, puesto que lo que en él se pretende es establecer en qué medida esa evolución de Pardo Bazán tiene su origen en la lectura de los novelistas rusos, cuestión que ya ha sido abordada por algunos críticos ${ }^{3}$. Es un hecho el gran impacto que

1. En las páginas 3-4 de la obra escribe: "For me, the crucial factor in this development is not a change of atmosphere, but an increasing interest in psychology, and the turning-point is not Una Cristiana-La prueba, but the most famous of Pardo Bazán's novels, Los pazos de Ulloa (1886). I shall be arguing [...] that in Los pazos de Ulloa one can detect one decisive change in her view of the novelist's activity; whereas before she saw this as being fundamentally the depiction of the external world, now she saw it as being the dramatisation of human psychology. Although there is no doubt that Pardo Bazán's novels of the 1890s are influenced to a greater or lesser degree by her Catholicism, it seems to me that to describe them as spiritual is to overstate the case and divert attention from the central issue of psychology".

2. En general, las opiniones a este respecto de diversos estudiosos — Gómez de Baquero, Correa Calderón, César Barja, López Sanz, Osborne, etc.- están recogidos por Clémessy y/o Hemingway. Aparte de éstos, entre los más reciente, puede citarse el de D.S. Whitaker (La quimera de Emilia Pardo Bazán y la literatura finisecular, Madrid, 1988), quien justifica el cambio interpretando las obras últimas de la autora como influidas por Nardau y Paul Bourget, así como por la filosofía shopenhaueriana, y habla de novela "decadente" tomando como paradigma la síntesis del estudio de Suzanne Nelbantian Seeds of" Decadence in the late Nineteenth-Century Novel (London, 1983).

3. R.E. Osborne, a este respecto, escribe: "Según muchos pensadores, incluso Pardo Bazán, hay gran afinidad entre el arte ruso y el español. [...] Balseiro, en su libro Novelistas españoles modernos, en el capítulo consagrado a Pérez Galdós, cita ejemplos sumamente interesantes de este fenómeno [...] Da ejemplos muy convincentes citando a Tolstoy, Ortega y Gasset, Portnoff, Chekov, Turguenev. Falla y otros [...] Allá por el año 1887 observó la condesa esta afinidad. Sin duda la analogía que pretendía ver nos ayuda a explicar su gran interés en esta nueva literatura del Este. 
causa a doña Emilia la lectura de las traducciones francesas de los escritores rusos del siglo XIX, que comenzó a hacer en 1886, y el interés que le suscitaron tanto las ideas nihilistas como la vida de los inmigrantes en París. Caracteriza el talante de doña Emilia su interés por el conocimiento, como es sabido, y, en este caso, indagó al máximo durante sus estancias anuales en la capital francesa, donde tenía acceso directo al mundo cultural y literario: como detalladamente informa Nelly Clemessy, conoció a Zola, a Daudet, a Huysmans, a Edmond Goncourt, etc. Sin embargo, el contacto con la cultura rusa lo obtuvo a través del vizconde de Vogüét. En 1887, doña Emilia pronunció en el Ateneo de Madrid una serie de conferencias que dan origen a los tres volúmenes publicados en el mismo año, los cuales llevan por título La revolución y la novela en Rusia. Curiosamente no llega a comprender bien a los dos grandes novelistas rusos, Tolstoi y Dostoievski, y aunque lee más al primero, el segundo la fascina. Sin embargo, en principio, en ninguno de ellos atisba el alcance de las innovaciones que sus obras aportan. Sobre ellos escribe:

Guerra y paz no es defendible: ni unidad, ni héroe, ni casi asunto; tan suelta y tan floja va la cinta que ata el relato y tan lentamente se desarrolla el argumento, que a veces el lector se ha olvidado ya del nombre de un personaje cuando vuelve a encontrárselo diez capítulos más allá. La vasta incoherencia del alma rusa, su indisciplina mental, su vaguedad y su afición a digresiones no pueden tener măs acabado símbolo en las letras $[\ldots]$.... más que Dostoievski, que ve la humanidad a través de su turbio pensamiento y su confuso espíritu, produce Tolstoi la impresión absoluta y suprema de la verdad, sin que sea posible decir, dada la admirable armonía de sus facultades, si acierta mejor al reflejar la realidad externa o la interna, si es más perfecto cuando describe, cuando dialoga o cuando estudia caracteres (pp. 392-393).

(Se refiere a Crimen y castigo) El argumento de la terrible novela es el siguiente: un estudiante comete un crimen, y acaba por confesarlo espontáneamente a la justicia. Ni más ni menos. Parece un suelto de la sección de noticias de un periódico, pero iqué análisis! [...] He oído afirmar que en el talento de Dostoievski influyó la personalidad fascinadora de Edgardo Poe. Las analogías son evidentes, pero nunca el autor de El escarabajo de oro con toda su intensi-

\footnotetext{
Aunque no tengo intención de estudiar la influencia de la literatura rusa en España, precisoes dedicar unas líneas a este punto. Primero, se notará que doña Emilia misma suftió esta influencia, y que la muestra claramente en varias de sus novelas, tales como La Quimera (1905) y La sirena negra (1908). Portnoff cree que también hay influencia de los novelistas rusos, especialmente de Tolstoy, en Galdós. Balseiro, en cambio, opone a esta idea opiniones poderosas. [...] Hay también indicios de influencia rusa en las ideas y los escritos de Palacio Valdés, Clarín, Ganivet y otros".

4. N. Clemessy informa sobre estos contactos en los siguientes términos: "Au cours de ses séjours dans la capitale française, Pardo Bazán entretint en outre des relations amicales avec des exilés russes, habitúes des milieus littérarires et artistiques. Elle connut, entre autres, Tikhomirov qui venait de publier en collaboration avec Savine un ouvrage intitulé: La Russie politique et sociale. Par cet intellectuel, qui avait été directement mêlé aux événements politiques de Russie, elle obtint de vive voix maintes informations sur le nihilisme [...] Pardo Bazán, avant d'écrire son étude critique, lut les pirncipaux ouvrages publiés à l'époque sur la Russie et sa littérature. Celui qui néanmoins lui apporte sans conteste Ies plus précieuses informations fut Le roman russe du viconte Melchior de Vogüé qui parut à Paris au début de 1886. Son auteur avait l'avantage de dominer parfaitement le russe et à la fois de connaître le pays et sa littérature. Il se proposait, grâce à son livre, d'initier le public français à la comprenhension des cheis d'ocuvre des grands romanciers contemporains" (Clemessy, 1973, pp. 111-112).
} 
dad sugestiva, con su imaginación febril, llegará a una sola de las tremendas análisis psicológicas de Crimen y castigo... [...] ¿es esto belleza? me dirán. Todo cuanto ha escrito Dostoievski tiene el mismo carácter: araña el alma, pervierte la imaginación y subvierte las nociones del bien y del mal hasta un grado increíble; unas veces nos produce el vértigo de los abismos del alma, como Hamlet; otras nos muestra la acción del genio maléfico en contra de la providencia, como Fausto, o se hunde en las negruras del remordimiento, como Macbeth, y siempre sus héroes parecen locos, maniáticos, energúmenos, filósofos de la hipocondría y de la desesperación. Pues con todo, digo que es belleza, belleza torturada, retorcida, satánica, pero intensa, grande y dominadora (pp. 374-377).

En marzo de 1886 leyó Crimen y castigo, y posterior es la lectura de El idiota, de cuyo príncipe Mishkin quiere ver Hemingway un reflejo en el epiléctico Serafín de Una cristiana (Hemingway, 1983, pag. 81). Lo que Vogüé llama "réligion de la souffrance", latente y patente en la novela rusa, pudo muy bien constituir un perfecto paradigma para una persona de tan marcado talante religioso como Pardo Bazán. En fin, esta cuestión, que debe plantearse como hipótesis, puede encontrar alguna respuesta en las opiniones de la autora sobre Turgueniev y Gontcharov:

No es mérito exclusivo de Turguenev el poner al lector en contacto con el mundo invisible, pues todos los grandes novelistas rusos poseen esta cuerda en su lira; mas Turguenev lo hace de un modo tan exquisito, con tal poesía, que alcanzando a producir en la imaginación el eretismo indispensable para la visión evocada por el novelista surja, él permanece sereno, en actitud de contemplar el extraño fenómeno psíquico. No hay sino leer El perro, Apariciones, y también Clara Militch, singular confesión de ultratumba( pág. 338).

[Se refiere a Oblomov] Es una novela en la que no hay más que un estudio de un estado psíquico, y sin embargo, ¡qué vida tan intensa late en sus páginas! (pág. 254).

Al plantear el influjo de la novela rusa en la literatura de Pardo Bazán, o si se quiere, la aportación de su concepción narrativa a la visión e interpretación de la vida que, desde 1886, como un continuum va adentrándose en el pensamiento de la novelista española, habrá que hacerlo desde el eclecticismo de la época ${ }^{5}$, pues si hablar de influjo directo siempre es arriesgado, en este caso lo sería doblemente, ya que lo que doña Emilia asimila a partir de aquellas lecturas es una nueva manera de concebir su relación, en cuanto narradora, con los personajes; $y$, por otra parte, y como base de lo primero, la importancia del fenómeno psicológico mental como elemento novelable.

En 1883, Dostoievski escribe en su cuaderno de notas: "Me llaman psicólogo; esto no es cierto; yo soy tan sólo un realista en el seṇtido superior, es decir, represento las profundidades del alma humana". En La novela rusa de Pardo Bazán se lee: "Hace tiempo que pienso y escribo que el realismo, para realizar debidamente su programa ha de abarcar materia y espíritu, tierra y cielo,

5. La misma Pardo Bazán, en Nuevo teatro crítico (1891), escribe: "Todo el que lea mis ensayos críticos comprenderá que no soy idealista, ni realista, ni naturalista, sino ecléctica".

6. Dato tomado de M.M. Batin, La poética de Dostoievski. 
admitiendo lo humano y lo sobrenatural". Y hay un momento, tal vez Una cristiana, en que el psicologismo mecánico de las leyes tainianas - herencia y medio- han dejado paso a lo incomprensible y a las respuesta inexplicables de la mente humana.

En otro orden de cosas, en Francia, la ruptura con la metafísica positivista cambia la visión cultural, y alcanzan el mayor éxito obras como el Essai sur les données immédiates de la conscience de Bergson (1889) o la Philosophie des Unbewussten de Von Hartmann (1877), que desarrolla el concepto de inconsciencia, y cuya traducción francesa también manejó Pardo Bazán.

Todas estas novedades serían las que llevarían a un cambio en la obra de la novelista. Por supuesto, siempre cabe plantearse si sin la lectura de Dostoievski, Gontcharov y Tolstoi las novelas de Pardo Bazán de los años noventa hubieran sido lo que son. Nuestra respuesta es negativa, tomando como base algunos datos que parecen evidenciar una intención de cambio: 1) Entre 1890 y 1896 , bien de manera total o bien de manera parcial, y a excepción de La piedra angular, las novelas de Pardo son narraciones en primera persona. La recuperación de la memoria en lo que Dorrit Cohn denomina "técnicas retrospectivas" al referirse a la narración en primera persona posibilita la exploración psicológica. De hecho, La sirena negra se ha interpretado como un proceso de descubrimiento del propio narrador, y está contada desde la primera persona narrativa y el monólogo autónomo. 2) Las colecciones de cuentos son posteriores a 1890; Harry Kirby, al darse cuenta de que éstos constituyen un buen exponente de las variaciones estilísticas de Pardo, advierte que "hay pocos datos de la evolución de la autora como cuentista" (Kirby, 1973, T. III, pp. 4-5). Asimismo, Alfonso Rey describe una de las fórmulas narrativas usadas por la autora: el narrador discute con un grupo de amigos sobre una opinión que expone, y la defiende refiriendo unos sucesos sobre los que ofrece su punto de vista (Rey, 1977). Esta técnica, así como otras utilizadas, permite a la autora entrar en la interioridad de los personajes de la historia sin grandes problemas que resolver en la relación entre la voz narradora y las voces de los personajes. 3) En fin, el análisis de La piedra angular puede ser el punto de mayor esclarecimiento a este respecto: si atendemos a cuestiones históricas, está escrita en 1891, y es la inmediatamente posterior a Una cristiana-La prueba, novelas que para muchos críticos marcan el comienzo de la segunda etapa creadora de la novelista; si atendemos a cuestiones temáticas, estamos ante el tema de la pena de muerte, importante, dada su relación con el de la culpa, para la decantación por parte de la autora de una visión y de una interpretación del mundo.

La crítica ha tenido opiniones muy dispares sobre ella. Por ejemplo, mientras César Barja la sitúa entre las "novelas sin valor característico particular" (Barja, 1964, pág. 310), Hemingway, aplicando otro tipo de visión y de análisis la coloca entre las mejores obras de la autora, y califica de injusto el olvido en que se la tiene (Hemingway, 1983, capítulo 5). Lo cierto es que estamos ante una novela planteada como tesis, y ante un tema que en el momento en que fue escrita se discutía en Europa desde los puntos de vista jurídico, antropológico y 
deontológico, a partir de las nuevas teorías sobre criminalidad que en Italia formulaban Lombroso, Ferri y Garófalo. Precisamente como exposición y defensa de las ideas y las teorías de la autora está concebida la tesis de la novela. Sabido es que doña Emilia criticó en debate público la escuela positivista italiana, $y$ también es conocido su interés por el tema y por las defensas de doña Concepción Arenal, a quien la novelista considera su maestra y a quien corrige en algunos puntos referidos a la posición de la mujer ante el derecho penal, puntos que aparecen en la novela planteados por dos de los personajes, Moragas y Febrero, pues si la mujer no es igual en derechos humanos y laborales, por qué ha de serlo ante el derecho penal, se preguntan.

Ahora bien, la defensa y propagación de unas ideas a través de la representación literaria que es la novela, dependerá en gran medida de la verosimilitud, y es aquí donde, en principio, la autora se encontrará con el primer escollo si se atiene a los principios creativos del Realismo-Naturalismo, pues en poco podrán ayudar los postulados literarios que estos movimientos propugnan para la defensa de una tesis ideológica compleja que ya nada tiene que ver con los planteamientos maniqueos de los años setenta?. El "realismo" que se impone a la tesis que en 1891 doña Emilia quiere representar es precisamente el que Dostoievski definía en el fragmento citado supra. Por tanto, La piedra angular presenta a la autora el reto de representar no la descripción de lo que vio o el reflejo del mundo que conoce, sino la demostración del beneficio social de las ideas abolicionistas. Su documentación no debe responder ya a la observación o a la copia de lo "real", tal como lo concibe el Naturalismo, sino que debe basarse en el estudio de teorías y en el alcance de su realización, todo lo cual deberá ser adaptado a un mundo de ficción que la autora sitúa en el ambiente marinedino, y en los hechos que en un momento dado de su monótono ciclo vital ocurren. En Nuevo teatro crítico, al referirse a la documentación de La piedra angular escribe: "solicité muchos datos y libros de personas que cultivaban la antropología jurídica; tuvieron la bondad de facilitármelos; yo procuré servirme de ellos como Dios me dio a entender para fines artísticos... y no hubo más".

Se impondrá, pues, un nuevo tipo de creación, una novela construida íntegramente sobre el eje discursivo, en la que los diálogos, las reflexiones y los recuerdos priman sobre la acción, que tan sólo en los capítulos dos y tres se da, y representada por la voz narradora; y priman asimismo sobre los acontecimientos, que se limitan al parricidio y a los que de él se derivan. Y se encuentra, por otra parte, una elaboración discursiva precisa que une el subjetivismo del punto de vista de los personajes con el hecho objetivo sobre el que se sustenta la tesis: el crimen. Se comprende así que, pese a ser un tema tan

7. Curiosamente en España, lo que la crítica recepcional entiende como "horizonte de expectativas", aún no está preparado para este tipo de tesis; así, la crítica que en 1892 le hace Leopoldo Pedreira no la concibe como tal; vemaos las siguientes afirmaciones como ejemplo: "La piedra angular no es una novela de tesis. Es un poema lleno de melancolía y humorismo. La accción está vista y sentida por la autora antes de la conclusiones que naturalmente se deducen de la novela". (Pedreira, 1892, pp. 113-114). 
en conexión con el pensamiento y con la conciencia, la autora haya elegido la tercera persona narrativa, pues este punto de vista puede permitirle una mayor dialéctica en las focalizaciones ideológicas ${ }^{8}$. El lema que encabeza la obra, tomado de San Pablo - ita ut serviamus in novitate spiritus, et non in vetustate litterae - señala el signo antagónico que preside la narración, al simbolizar no sólo la actitud de los dos personajes opuestos, como señala Hemingway (Hemingway, 1983, pág. 96), sino también el nuevo espíritu de las fïlosofías mencionadas, que se encuentran latentes en la novela como paradigma ideológico.

Es cierto que en 1981, cuando estaba escribiendo la obra, doña Emilia presenció en Madrid, a petición propia, el ajusticiamiento por garrote vil de una mujer, Higinia Balaguer, pero también es cierto que de esa observación sólo pasa a La piedra angular el rechazo a la pena capital y el afianzamiento en sus ideas feministas. Asimismo, en carta a Giner fechada poco después de la publicación de la novela, dice haber conocido a los modelos de los dos personajes principales. Pero en literatura, los modelos más o menos próximos o remotos siempre existen, sin que necesariamente la concepción literaria del autor sea realista.

La historia o argumento es simple: el verdugo de una capital de provincia, Marineda, requiere la asistencia de un prestigioso médico. En relación con la sociedad en que viven, uno y otro representan, respectivamente, el rechazo y el respeto, la marginalidad y la integración. El encuentro de los dos personajes es el móvil que pone en marcha el desarrollo de la historia, y sus respectivos hijos constituyen dentro de ésta una especie de resorte de las conciencias de los padres, y, en última instancia, serán el origen del desenlace. Un crimen cometido en una aldea cercana a Marineda es el detonante que pone en evidencia el tema de la novela, al tiempo que lleva la acción hacia el desenlace.

Nuevos personajes aparecen a partir de este episodio, y son de especial relevancia los capítulos VIII Y XIX, en donde, en el casino de Marineda, dos grupos ideológicos - liberales y conservadores - defienden sus respectivos puntos de vista sobre la pena de muerte ante el referente del parricidio de La Erbeda. Personajes como Julio Febrero y Arturo Cáñamo, partidarios el uno de la escuela positivista italiana, y de la legislación tradicional española de Meléndez Valdés el otro, no tienen prácticamente ninguna función en la historia: simplemente representan ideologías, unas ideologías que chocan con las del doctor Moragas, quien al admitir el libre albedrío encarna la tercera vía de pensamiento, la de la escuela idealista que defiende la educación del culpable; y a partir de ella surge la acción, pues en su postura vital-personal y desde su conciencia profesional, Moragas defenderá la redención individual de la persona.

8. Para algunos críticos no existe diferencia cualitativa de representación entre los relatos en tercera persona y los relatos en primera persona. Así, por ejemplo, Wayne C. Booth. Dorrit Cohn, por el contrario, señala las diferencias técnicas, y la incidencia ideológica que conlleva cada una de ellas. 
El resto, son las voces de Marineda, el "coro", constituído por representantes de clases sociales y de oficios, las cuales, si en un principio condenan el crimen, en el momento del veredicto clamarán por el indulto. Y dirigiendo al "coro" no puede faltar, como es natural, el papel de la prensa. La misma autora, en repetidas ocasiones, de manera más o menos explícita, presenta la función literaria de esas voces.

Mucho eco dostoievskiano se percibe en la personalidad de Moragas, defensor del leitmotiv que caracteriza la obra: la redención. Es este personaje el redentor cuya acción se dirige al entorno de Rojo, el redimio. Uno y otro, antagonistas, se disputan el protagonismo de la historia; y para la caracterización y la acción de ambos, utiliza la autora estrategias que revelan la dramatización de los dos puntos de vista: el conato de psicoanálisis que supone el careo a que la autora los somete en un momento determinado, es el ejemplo más claro de esta técnica compositiva en la que el propio personaje va configurando su personalidad y defendiendo su función.

Por otra parte, la información que ofrece la narración de los dos personajes está presentada con distintas fórmulas discursivas, pues mientras a Moragas lo llegamos a conocer a través de la psiconarración de la voz narradora, de Rojo sabemos a través de su propio monólogo, normalmente con la técnica del monólogo narrado. De hecho, la autora llega a implicarse ideológicamente con curiosas fórmulas narrativas para identificarse ideológicamente con Moragas. Incluso hay un dato discursivo más que marca el antagonismo entre los dos personajes: de Moragas importan sus proyectos; de Rojo, su pasado. Ahora bien, la versión que Rojo da de sí mismo en su propio discurso es tan buena desde el punto de vista lógico y psicológico como la que la autora da de Moragas desde el punto de vista filosófico y moral, y en última instancia siempre queda latente la cuestión que plantean Febrero, Rojo e incluso, al final, Moragas: si es más culpable de la muerte del reo el que firma la sentencia o el que la ejecuta. Sin embargo, la cuestión social que refiere Febrero en el capítulo IX reviste al verdugo con la lacra de la culpa.

Si la definición ideológica de una novela viene dada fundamentalmente por el tema y su tratamiento, por el leitmotiv y los motivos, en La piedra angular estos aspectos remiten al mundo de la novelística rusa decimonónica: la pena de muerte, la culpabilidad, las inculpaciones, el aislamiento, la redención, y, en última instancia, el enfrentamiento del individuo a sí mismo y a la sociedad; y tal vez subyacente como principio generador, el presentimiento de la soledad óntica que late en esos diálogos que no llegan a ser tales, como ha demostrado Bajtin que ocurre en las novelas de Dostievski, y como se da también en los monólogos y en los razonamientos de Tolstoi.

En La piedra angular, los monólogos de Moragas son frecuentes, unos monólogos en los que el personaje se dirige a sí mismo con un tú autorreflexivo y entabla consigo mismo un diálogo que le permite percibir la idea clara y definida, o bien le permite un desdoblamiento personal cuando le habla su conciencia o su instinto médico. 
Al igual que en la obra de Dostoievski, tampoco en ésta de Pardo se da la comunicación entre los personajes; cada uno de ellos habla y defiende su punto de vista, y actúa según corresponde a sus ideas, con absoluta consecuencia, rasgo que lleva a situaciones y actos límites a los personajes principales: al uno a acoger bajo su techo y junto a su hija al hijo del verdugo, lo que es tanto como retar a la sociedad marinedina; al otro, al suicidio. Ambos actos están encaminados a la redención de Telmo: el primero mediante la integración social; el segundo, mediante la liberación de su pasado, como si aquélla sólo pudiera darse con la desaparición del padre.

Ni siquiera Telmo y Nené pueden comunicarse en el capítulo XVI: cada uno ve la realidad del juego desde su punto de vista. Y en este orden de cosas hay que ver, en fin, el último dato significativo: la interpretación que unos personajes hacen de otros puede ser tan desajustada como la de Cáñamo sobre Febrero.

Esta incomunicación hace que en la novela reine un cierto desorden: si la acción, decíamos, es algo que se desvanece, que apenas existe con independencia del acaecer puramente cotidiano de Marineda, el tiempo del relato se reduce a cuatro o cinco días de los cuatro o cinco meses que debe de durar el de la historia (desde la primavera hasta el otoño). En consonancia con este rasgo estructural está el temperamento de Moragas, que la autora presenta como un contraste de vehemencia y laxitud.

Sin embargo, la estructura está perfectamente trazada, y deja ver el intento de la autora de despojar el relato de todo aquello que no sea estrictamente esencial para demostrar su tesis. La elaboración es interesante por cuanto los sucesos de los dos primeros días se enmarcan en los capítulos I a VII y VIII a XII, respectivamente. El primer día está presentado como una sucesión de acciones y de momentos que se suceden desde las 13:30 horas hasta la entrada de la noche, y con una técnica precisa, vuelve al tiempo donde quedó su acción con otra acción diferente. En el segundo, que empieza con el despertar de la ciudad, tienen lugar los diálogos en el casino, en casa de Rojo, entre Moragas y Febrero en la calle, etc.

La representación del segundo día cambia radicalmente: todo gira alrededor del núcleo argumental, y puede reducirse a la noticia escueta de un diario, característica básica que la autora atribuía a Crimen y castigo (cf. supra). Y a partir de esa noticia, los comentarios, las conjeturas, los juicios de valor, las opiniones... El comienzo - “Despertóse la capital marinedina comentando, rumiando, desfigurando"- es la catáfora —símbolo y síntesis al mismo tiempo- con la que la autora abre el relato del día, implicándose incluso con un juicio de valor producto de su estrategia narrativa: "Iba a decir saboreando la noticia del crimen de La Erbeda si no me pareciera calumnia".

En estos días, la tesis ha quedado planteada; el desarrollo posterior de la historia le añade la parte fundamental del autoconvencimiento de Moragas y el triunfo de su postura: él es el único que ha podido conseguir que el día de autos 
no se ajusticie a los reos. Lo que sucede el día del juicio y la "víspera del día siniestro" (días tercero y quinto) y "un día al final del verano" (día cuarto) son las consecuencias respectivas de los días primero y segundo. Entre los dos de la primavera y los tres del otoño ha transcurrido un periodo en el que Moragas ha reflexionado y en el que ha recibido la información fidedigna del móvil del crimen.

Pues bien, si éstas son las características que rigen la presentación de la novela en lo que se refiere a la representación de relato-historia, la configuración de la narración en su relación con el relato presenta una serie de estrategias concernientes al discurso. Hemos hecho ya referencia a varios tipos de características discursivas de las que la autora se vale, y en este sentido, la pluralidad de formas que en el último tercio del siglo XIX suponen novedades en cuanto a la expresión del discurso referido, son utilizadas con profusión para fines comunicativos precisos ${ }^{9}$. Especial interés cobra la elaboración estratégica con la que la autora incluye en la narración la presencia del lector implícito, o los casos en los que la voz narradora se dirige sin más ambages a una segunda persona, y le muestra con especial fuerza ilocutiva tanto la intención de los personajes como su propio punto de vista; o bien los casos en que su propia opinión se impone, ya porque sabe el dato oportuno, ya porque conoce el comportamiento humano. $\mathrm{Y}$ no es menos digno de análisis el cambio narrativo que tiene lugar en el capítulo XVI: la confirmación de la sentencia del veredicto como algo irrevocable es información transmitida a los lectores en tiempo presente, lo que confirma el hecho a través de los valores aspectuales propios de su morfema, y los del sentido del presente gnómico.

El análisis de la narración podría prolongarse, pues La piedra angular es un ejemplo de buena creación en lo que se refiere a la representación de las voces referidas. Sin embargo, nos limitaremos al de los aspectos que suponen innovación, pues si es cierto que en la obra aún quedan rasgos del naturalismo de la autora, encontramos en este su nuevo rumbo estrategias de enunciación que contrastan con las formulaciones anteriores.

Como consecuencia de la aplicación de un nuevo concepto de documentación y de representación, una formalización como puede ser la descripción desaparece, y es sustituída en la construcción de la verosimilitud mediante fundamentos textuales de distinta índole: por un lado, unos que remiten a los principios clásicos de oralidad, y, por otro, la inclusión de elementos simbólicos que nos sitúan en los años finales del siglo. Son tres fundamentalmente los aspectos representativos que cambian: 1) la transposición de lo observado, 2) la ironía, y 3) la descripción, que son sustituídas respectivamente por 1) la transposición de lo oído, 2) la parodia, y 3) el simbolismo.

Es decir, toda la rémora costumbrista que el narrador naturalista español sigue utilizando como resorte de connivencia o complicidad con el lector, a quien presenta un mundo verosímil de hechos cotidianos, es sustituida por la

9. Sobre el discurso referido en la historia de la literatura puede verse Batjin 1929. Tercera parte. 
fórmula de la documentación textual, que representa al lector la certeza de que el hecho está verificado, y en la novela aparece conjugada y contrastada con la de la inverosimilitud de ciertos géneros y obras literarias.

En la misma línea de recuperación de la oralidad está la inclusión de fragmentos paródicos: las tesis jurídicas de Grocio, Pufendorf o Beccaría, son manipuladas, subvertidas; lo mismo que las teorías de Clausewitz en la pseudobatalla, cuyo resultado es una lapidación; y las ideas de Fourier corren la misma suerte en esa especie de falansterio programado por Moragas para acoger a los iguales en ideas. Precisamente, la crítica que en 1892 le hace Baltasar Champseur es negativa al referirse en estos pasajes, tal vez por no haberse dado cuenta de que estaba ante construcciones paródicas.

Por el contrario, ya no aparecen en La piedra angular lo que algunos críticos interpretan como ironía, y que Germán Gullón ve como un acercamiento del narrador al lector (Gullón, 1976, pp. 48-49), es decir, la utilización por parte de la autora de calificativos que suelen ser una especie de descalificaciones que siempre sorprenden y divierten a los lectores. Por ejemplo, en la presentación de Leocadia en El cisne de Vilamorta escribe sobre los amantes: "Al ver tan guapo chico recostado en el pecho de aquella jamona de apacible y franca fealdad, era lógico tomarles por hijo y madre".

La descripción realista es considerada hoy por la crítica como una digresión temática ${ }^{10}$. Pues bien, en La piedra angular, tales descripciones sólo aparecen en alguna referencia médica, y lo que se da es un tipo de descripción simbolista o una descripción de la interioridad del personaje, o incluso la unión de ambas en un símbolo. Por ejemplo, la descripción de la vivienda de Rojo y la opinión de Moragas sobre el lugar; la descripción física de Telmo y la comparación de su carita con la de un negro (hay que tener en cuenta la absoluta segregación de que es víctima el muchacho en Marineda); o bien la muerte de Orosia, personaje muy parecido a la parricida: la descripción de la muerte que hacen las vecinas enseña a Moragas que la salida para estas mujeres sólo tiene dos puertas: matar o morir. La impunidad en que queda el crimen de Orosia fortalece más la decisión que había tomado Moragas en la cárcel después de visitar a la parricida, mientras encendía el fósforo, un nuevo símbolo, el de llevar a cabo una tarea imposible (en este caso el de conseguir el indulto para la mujer), símbolo utilizado con este valor en la literatura de la época, según señala Walter Benjamin en su estudio sobre Baudelaire. La idea que representa este símbolo estaba ya escrita en el capítulo IX, formulada por Moragas.

En fin, las alteraciones a nivel de construcción del relato y de la narración que se han señalado, indican que estamos ante un cambio ideológico y a las puertas de un nuevo periodo literario. Ante una noticia como la de el crimen de La Erbeda, el Realismo-Naturalismo hubiera narrado los hechos, hubiera des-

10. Teóricos estructuralistas - Barthes, Hammon, etc.— la definen como la unión del significante con el referente. 
crito los detalles. En 1891, doña Emilia Pardo Bazán formula una tesis y construye una representación mediante los principios literarios de la oralidad: lo que sucedió en La Erbeda no es descrito ni narrado: circulan versiones, y, al final, sólo sabremos las causas y las consecuencias a través del abogado defensor. El tema y la narración de la novela han sido representados a través de un juego de valoraciones sobre una noticia periodística.

\section{BIBLIOGRAFÍA}

BAKHTINE, Mikhail. (1929). 1977. Le marxisme et la philosophie du langage, Paris, Editions de Minuit.

BATJin, Mijál. (1979). 1986. Problemas de la poética de Dostoievski, México, Fondo de Cultura Económica.

BARJA, César. 1964. Libros y autores contemporáneos, Nueva York, Las Américas.

BENJAMIN, Walter. 1955. Schriften VIII, Frankfurt am Main, Shurkamp Verlag.

CLEMESSY, Nelly. 1973. Emilia Pardo Bazán, romancière (La critique, la théorie, la pratique), Paris, Centre de Recherches Hispaniques, 2 vols.

COHN, Dorrit. 1978. Transparent Minds. Narrative Modes for Presenting Consciousness in Fiction, Princeton, Princeton University Press.

CHAMPSEUR, Baltasar. 1892. "La piedra angular. Por Emilia Pardo Bazán", Revista de España, 139, pp. 178-194.

GULLÓN, Germán. 1976. El narrador y la novela del siglo XX, Madrid, Taurus.

HEMINGWAY, Maurice. 1983. Emilia Pardo Bazán. The Making of a Novelist, Cambridge, Cambridge University Press.

KIRBY, Harry. 1973. Introducción a Obras completas de Emilio Pardo Bazán, Madrid, Aguilar.

OSBORNE, R.E. 1954. "Emilia Pardo Bazán y la novela rusa", Revista Hispánica Moderna, 20, pp. 273-281.

PEDREIRA, L. 1892. "La piedra angular", Revista contemporánea, 30 de enero de 1892, tomo LXXXV, vol. II, pp. 113-119.

RUBIA BARCIA, M. 1960. "La Pardo Bazán y Unamuno", Cuadernos americanos, CXII, pp. 240-263.

REY, Alfonso. 1977. "El cuento sicológico de Pardo Bazán”, Hispanófila 59, pp. 19-30.

VARELA JÁCOME, B. 1973. Estructuras novelísticas de Emilia Pardo Bazán, Santiago de Compostela, CSIC, Instituto P. Sarmiento. 